\title{
The Injury Rate in National Football League Players Increased Following Cancellation of Preseason Games Because of COVID-19
}

\author{
Hayden P. Baker, M.D., Sean Pirkle, M.D., Michael Cahill, B.A., Manoj Reddy, M.D., \\ Daniel Portney, M.D., and Aravind Athiviraham, M.D.
}

\begin{abstract}
Purpose: To investigate the injury rate in National Football League (NFL) athletes during the first 4 weeks of the 2020 NFL season. Methods: This study was a retrospective review of all NFL players who were placed on the injury report during the preseason and the first 4 weeks of the regular season from the 2016-2017 through the 2020-2021 NFL regular seasons. Players' dates of injury were cross-referenced with an absence of statistics from the respective games for which they were ruled out so as to ensure accuracy. Injury rates were calculated per 1,000 athletic exposures. Relative risk with 95\% confidence intervals compared injury rates between the 2 cohorts. Results: Over the course of the study period of 4 NFL seasons, 3,025 injuries were reported. Of the 3,025 injuries reported, 582 (19\%) occurred during weeks 1-4 of the 2020-2021 regular season, whereas 1,292 (53\%) occurred during preseason weeks 1-4, and 1,151 (38\%) occurred during regular-season weeks 1-4 of NFL seasons 2016-2017, 2018-2019, and 2019-2020. There was a significant increase in the injury rate during weeks 1-4 of the 2020-2021 regular season for all comparisons with the injury rate both during the preseasons and the regular seasons of 3 recent past NFL seasons. Conclusions: The rate of injury in NFL players during weeks 1-4 of the 2020-2021 regular seasons was significantly higher than during 3 recent past NFL preseasons and regular seasons. Level of Evidence: Level IV, diagnostic case series.
\end{abstract}

B ecause of the rising number of positive Covid-19 tests observed in National Football League (NFL) players during the summer of 2020, the NFL suspended the 2020 preseason on July 21, 2020. ${ }^{1}$ Suspension of play based on concern regarding rising numbers of cases of Covid-19 in the United States was widespread and not limited to the NFL; similar trends were observed across all sports and levels, including high school, collegiate and professional levels. To mitigate potential exposures to Covid-19, NFL team training

From the Department of Orthopaedic Surgery, The University of Chicago, Chicago, Illinois, U.S.A.

The authors report the following potential conflicts of interest or sources of funding: Full ICMJE author disclosure forms are available for this article online, as supplementary material.

The study was performed at The University of Chicago

Received December 31, 2020; accepted May 6, 2021.

Address correspondence to Hayden Baker, M.D., 5758 South Maryland Avenue,Department 4B, Chicago,IL 60637,U.S.A.E-mail:hpbaker65@ gmail.com

(C) 2021 THE AUTHORS. Published by Elsevier Inc. on behalf of the Arthroscopy Association of North America. This is an open access article under the CC BY-NC-ND license (http://creativecommons.org/licenses/by-nc-nd/4.0/). 2666-061X/202064

https://doi.org/10.1016/j.asmr.2021.05.002 camp roster sizes were limited to 80 players. ${ }^{1}$ Typically, the NFL preseason serves as the primary time for preparing athletes for the rigors of the upcoming NFL season. However, given this unprecedented stoppage of preseason training and teams' inability to continue with practice and games due to social-distancing precautions, athletes were forced to train and condition on their own. We speculated that in the absence of organized team activities, athletes developed sports deconditioning.

Previous studies have demonstrated that fatigue and deconditioning may place athletes at a higher risk for injury. The International Olympic Committee identified absolute load, calendar congestion and psychological load to be closely associated with injury risk through a variety of mechanisms. ${ }^{2}$ Excessive training that exceeds the body's loadbearing capacity causes microtrauma to tendons, muscles and bones and is the cause of overuse injuries. $^{3-8}$

In light of these findings that highlight the association between fatigue and risk of injury, investigating modifiable causes influencing athletes' levels of fatigue is a critical step in reducing risk of injury. The purpose of this study was to investigate the injury rate in NFL athletes during the first 4 weeks of the 2020 NFL 
Table 1. National Football League Injuries During Preseason and Regular Seasons Weeks 1-4 From 2016-2020

\begin{tabular}{|c|c|c|c|c|}
\hline \multirow[b]{2}{*}{ Week } & \multicolumn{4}{|c|}{ Year } \\
\hline & 2016 & 2018 & 2019 & 2020 \\
\hline Preseason week 1 & 63 & 176 & 95 & Canceled \\
\hline Preseason week 2 & 77 & 138 & 228 & Canceled \\
\hline Preseason week 3 & 112 & 120 & 102 & Canceled \\
\hline Preseason week 4 & 47 & 97 & 37 & Canceled \\
\hline Preseason Total & $299(42 \%)$ & $531(57 \%)$ & $462(58 \%)$ & 0 \\
\hline Regular season week 1 & 48 & 100 & 76 & 141 \\
\hline Regular season week 4 & 89 & 111 & 95 & 146 \\
\hline Regular season total & $413(58 \%)$ & $400(43 \%)$ & $338(42 \%)$ & 582 \\
\hline Total & 712 & 931 & 800 & 582 \\
\hline
\end{tabular}

season. Our hypothesis was that the observed injury rate during the first month of the 2020-2021 NFL season would be significantly higher when compared to past seasons.

\section{Methods}

\section{Data Collection}

This study was a retrospective review of all NFL players who were placed on the injury report during the preseason and the first 4 weeks of the regular season from the 2016-2017 through the 2020-2021 regular NFL seasons. The data were compiled using publicly available injury reports (Appendix). The sources used publish a weekly injury reports detailing the names of the players injured, their teams and a brief description of each injury. At least 2 different sources were used to cross-reference injury information. To verify each player's date of injury, we confirmed that each player's reported injury date corresponded to an absence of statistics from the respective games for which he was ruled out. These methods are in accordance with previously published protocols. $^{9-13}$ When collecting data, we noted that the 2017-2018 records were incomplete, so we excluded them from the study. We thought that data from 3 recent past seasons were adequate to compare data from 2020.

Team records available for individual team websites were used to collect demographic information. Our dataset included each player's name, position, team, pathology, age at injury, date of injury, and season. Data for the 2020 season were collected prospectively, so we were unable to determine games missed due to injury because the 2020 NFL season was ongoing when this study was performed.

\section{Definitions}

Reportable injuries were based on the following criteria: that the injury necessitated a team physician's referral or emergent care and that it resulted in missed athletic activity. An athlete-exposure (AE) was defined as 1 athlete's participation in 1 game in which he was exposed to potential injury.

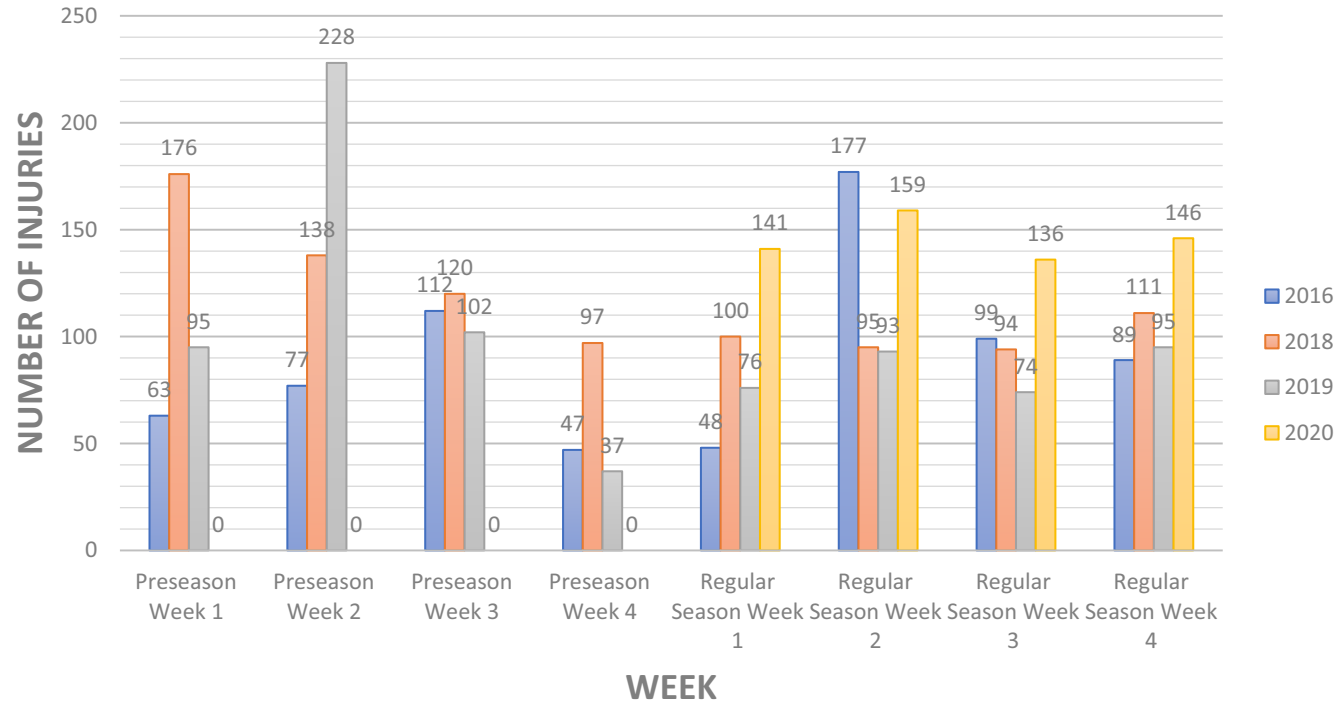

Fig 1. National Football League injures during preseason and regular seasons weeks 1-4 from 2016-2020. 
Table 2. National Football League Injuries per Athlete Exposure During Preseason and Regular Seasons Weeks 1-4 From 20162020

\begin{tabular}{|c|c|c|c|c|}
\hline & \multicolumn{2}{|c|}{ Injuries per 1000 Athletic Exposure } & \multirow[b]{2}{*}{ Relative risk Ratio } & \multirow[b]{2}{*}{$P$ Value } \\
\hline & 2016-2019 & 2020 & & \\
\hline Preseason week 1 & 2.4 & Canceled & 2.14 & 0.001 \\
\hline Preseason week 2 & 3.2 & Canceled & 1.82 & 0.001 \\
\hline Preseason week 3 & 2.4 & Canceled & 2.07 & 0.001 \\
\hline Preseason week 4 & 1.9 & Canceled & 4.09 & 0.001 \\
\hline Regular season week l & 2.8 & 5.2 & 1.88 & 0.01 \\
\hline Regular season week 2 & 4.5 & 5.9 & 1.31 & 0.01 \\
\hline Regular season week 3 & 3.3 & 5.0 & 1.53 & 0.01 \\
\hline Regular season week 4 & 3.6 & 5.4 & 1.48 & 0.01 \\
\hline
\end{tabular}

\section{Data and Statistical Analysis}

Data analysis was conducted using SPSS 25 (SPSS, Chicago, IL). Injury rates were calculated per 1,000 AEs using the following calculations: for the first 3 preseason games where NFL teams carry 90 players on the roster (total number of injuries $\times 1,000 /$ total number of AEs $(\mathrm{AEs}=90$ players $* 32 \mathrm{NFL}$ teams * number of games) $)$; for the fourth preseason game, where NFL teams cut the roster to 75 players (total number of injuries $\times 1,000$ / total number of AEs (AEs $=75$ players * 32 NFL teams * number of games)); and for the regular-season games (total number of injuries $\times 1,000 /$ total number of AEs $($ AEs $=53$ players * 32 NFL teams * number of games $)$. Risk ratio with $95 \%$ confidence intervals (CIs) compared injury rates between the 2 cohorts. Risk ratios were calculated by comparing both weeks 1-4 from the preseason and the regular NFL seasons in 2016-2017, 2018-2019 and 2019-2020 to the 2020-2021 season. Week 1 of the 2020-2021 NFL season was compared to both past preseason and regular-season week 1 ; this method of comparison was continued for weeks 2-4. Continuous variables were statistically compared using a 2 -tailed $t$ test, whereas categorical variables were compared using the $\chi^{2}$ test. Statistical significance was set at $p \leq 0.05$.

\section{Results}

Over the course of the study period of 4 NFL seasons, 3,025 injuries were reported. Of those, 582 (19\%) occurred during weeks 1-4 of the 2020-2021 regular season, while 1,292 (53\%) occurred during preseason weeks 1-4, and 1,151 (38\%) occurred during regularseason weeks 1-4 of NFL seasons 2016-2017, 20182019 and 2019-2020 (Table 1) (Fig 1). There was a significant increase in the injury rate during weeks 1-4 of the 2020-2021 regular season for all comparisons with the injury rate, both during the preseason and the regular season of the 3 recently past NFL seasons (Table 2).

Positional breakdowns demonstrated that wide receivers, safeties and linebackers sustained the most injuries during the study period (Table 3). Most of the reported injuries were to the knee 473 (16\%), hip/groin $347(11 \%)$ or ankle $316(10 \%)$ (Table 4$)$. The majority of injuries occurred secondary to player contact: 2,151 (71\%). Undisclosed injuries identified numbered 343 $(11 \%)$.

\section{Discussion}

The most important finding of this study was that the injury rate during weeks 1-4 of the 2020-2021 NFL season was significantly higher than the injury rates during weeks 1-4 of the 2016-2017, 2018-2019 and 2019-2020 NFL preseasons and regular seasons. The findings of our study confirmed our hypothesis that players were at a higher risk of injury during the early 2020-2021 regular season following cancellation of preseason games due to Covid-19. Our findings highlight the importance of the NFL training camp in preparing NFL athletes for the rigors of the NFL regular season and its influence on injury prevention.

Similar to the findings of Feeley et al. ${ }^{14}$ and Elliott et al., ${ }^{15}$ we observed that more injuries occurred during the first 2 weeks of the NFL preseason (777) (60\%)

Table 3. Positional Breakdown of Injuries

\begin{tabular}{lccccc}
\hline Positional Breakdown & \multicolumn{5}{c}{} \\
\hline Offense (quarterback) & 2016 & 2018 & 2019 & 2020 & Total \\
Quarterback & 22 & 20 & 22 & 9 & 73 \\
Runningback & 65 & 97 & 88 & 45 & 295 \\
Wide receiver & 97 & 138 & 102 & 95 & 432 \\
Tight end & 62 & 64 & 66 & 34 & 226 \\
Center & 14 & 20 & 14 & 9 & 57 \\
Offensive tackle & 41 & 83 & 62 & 52 & 238 \\
Guard & 29 & 43 & 28 & 30 & 130 \\
Fullback & 0 & 2 & 5 & 3 & 10 \\
Defense & 2016 & 2018 & 2019 & 2020 & Total \\
Defensive tackle & 90 & 54 & 95 & 39 & 278 \\
Defensive end & 23 & 63 & 40 & 47 & 173 \\
Linebacker & 103 & 119 & 102 & 79 & 403 \\
Cornerback & 44 & 77 & 62 & 77 & 260 \\
Safety & 117 & 139 & 108 & 56 & 420 \\
Special teams & 2016 & 2018 & 2019 & 2020 & Total \\
Kicker & 4 & 12 & 5 & 6 & 27 \\
Long snapper & 0 & 0 & 1 & 1 & 2 \\
\hline
\end{tabular}


Table 4. Injuries in National Football League Games by Season, Anatomic Site and Injury Mechanism

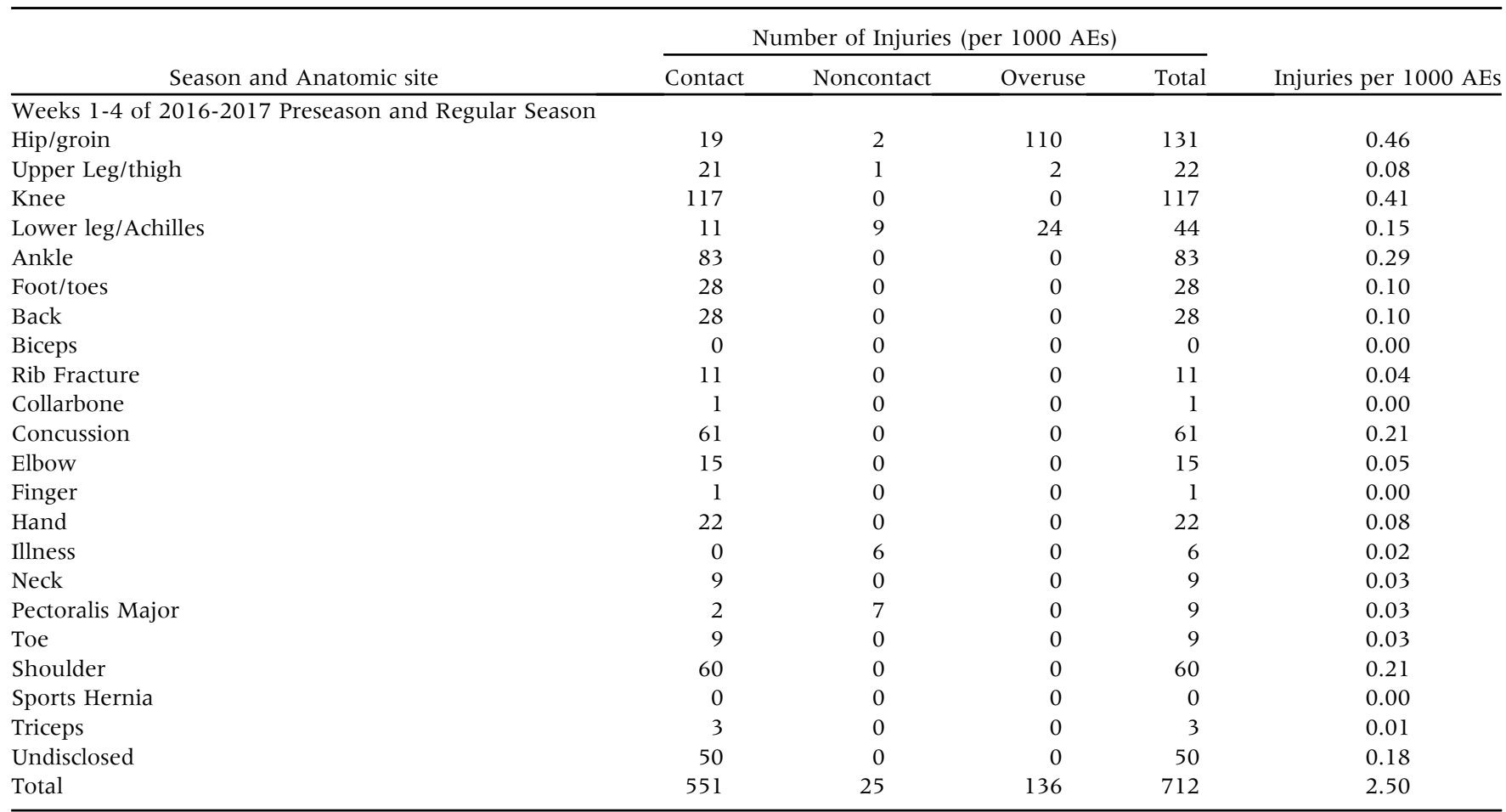

Number of Injuries (Injuries per 1000 AEs)

Weeks 1-4 of 2018-2019 preseason and regular season

Hip/groin

Upper leg/thigh

Knee

Lower leg/Achilles

Ankle

Foot/toes

Back

Biceps

Rib fracture

Collarbone

Concussion

Elbow

Finger

Hand

Illness

Neck

Pectoralis major

Toe

Shoulder

Sports hernia

Triceps

Forearm

Undisclosed

Total

\begin{tabular}{|c|c|}
\hline 24 & 50 \\
\hline 0 & 12 \\
\hline 159 & 0 \\
\hline 23 & 6 \\
\hline 94 & 0 \\
\hline 46 & 0 \\
\hline 0 & 21 \\
\hline 0 & 2 \\
\hline 13 & 0 \\
\hline 0 & 0 \\
\hline 63 & 0 \\
\hline 14 & 0 \\
\hline 6 & 5 \\
\hline 16 & 0 \\
\hline 0 & 16 \\
\hline 7 & 0 \\
\hline 6 & 0 \\
\hline 10 & 0 \\
\hline 63 & 0 \\
\hline 0 & 0 \\
\hline 0 & 3 \\
\hline 4 & 0 \\
\hline 132 & 0 \\
\hline 680 & 115 \\
\hline
\end{tabular}

9
109
0
18
0
0
0
0
0
0
0
0
0
0
0
0
0
0
0
0
0
0
0
136

83

0.29

0.42

0.56

0.16

0.33

0.16

0.07

0.01

0.05

0.00

0.22

0.05

0.04

0.06

0.06

0.02

0.02

0.04

0.22

0.00

0.01

0.01

0.46

3.26

Number of Injuries (Injuries per 1000 AEs)

Season and Anatomic site

Contact

Noncontact

Overuse

Total

Injuries per 1000 AEs

Weeks 1-4 of 2019-2020 preseason and regular season

Hip/groin

Upper leg/thigh

Knee

20
13
108

22
39
0

22
40
0

64
92
108

0.22

0.32

0.38 
Table 4. Continued

\begin{tabular}{|c|c|c|c|c|c|c|}
\hline & & \multicolumn{4}{|c|}{ Number of Injuries (Injuries per $1000 \mathrm{AEs}$ ) } & Injuries per $1000 \mathrm{AEs}$ \\
\hline \multicolumn{2}{|c|}{ Lower leg/Achilles } & 21 & 26 & 0 & 47 & 0.16 \\
\hline \multicolumn{2}{|l|}{ Foot/toes } & 37 & 0 & 0 & 37 & 0.13 \\
\hline \multicolumn{2}{|l|}{ Back } & 0 & 23 & 0 & 23 & 0.08 \\
\hline \multicolumn{2}{|l|}{ Biceps } & 0 & 3 & 0 & 3 & 0.01 \\
\hline \multicolumn{2}{|l|}{ Rib fracture } & 6 & 0 & 0 & 6 & 0.02 \\
\hline \multicolumn{2}{|l|}{ Concussion } & 65 & 0 & 0 & 65 & 0.23 \\
\hline \multicolumn{2}{|l|}{ Elbow } & 11 & 0 & 0 & 11 & 0.04 \\
\hline \multicolumn{2}{|l|}{ Finger } & 13 & 0 & 0 & 13 & 0.05 \\
\hline \multicolumn{2}{|l|}{ Hand } & 15 & 8 & 0 & 23 & 0.08 \\
\hline \multicolumn{2}{|l|}{ Illness } & 0 & 6 & 0 & 6 & 0.02 \\
\hline \multicolumn{2}{|l|}{ Neck } & 17 & 0 & 0 & 17 & 0.06 \\
\hline Pectoralis major & & 6 & 0 & 0 & 6 & 0.02 \\
\hline Forearm & & 0 & 0 & 0 & 0 & 0.00 \\
\hline Undisclosed & & 129 & 0 & 0 & 129 & 0.45 \\
\hline Total & & 611 & 127 & 62 & 800 & 2.81 \\
\hline & & Numbe & Injuries & & & \\
\hline Season and Anatomic site & Contact & Noncontact & Overuse & & & Injuries per $1000 \mathrm{AEs}$ \\
\hline 2020-2021 & & & & & & \\
\hline Hip/groin & 21 & 10 & 38 & & & 0.64 \\
\hline Upper leg/thigh & 0 & 13 & 78 & & & 0.84 \\
\hline Knee & 26 & 63 & 0 & & & 0.82 \\
\hline Lower leg/Achilles & 10 & 26 & 0 & & & 0.33 \\
\hline Finger & 15 & 0 & 0 & & & 0.14 \\
\hline Hand & 5 & 0 & 0 & & & 0.05 \\
\hline Illness & 0 & 33 & 0 & & & 0.3 \\
\hline Neck & 8 & 0 & 0 & & & 0.07 \\
\hline Pectoralis major & 8 & 0 & 0 & & & 0.07 \\
\hline Toe & 11 & 0 & 0 & & & 0.1 \\
\hline Shoulder & 41 & 0 & 0 & & & 0.38 \\
\hline Sports hernia & 0 & 2 & 0 & & & 0.02 \\
\hline Triceps & 0 & 1 & 0 & & & 0.01 \\
\hline Undisclosed & 32 & 0 & 0 & & & 0.3 \\
\hline Total & 309 & 157 & 116 & & & 5.4 \\
\hline
\end{tabular}

AE, athlete exposure.

when compared with the second 2 weeks (515) (40\%). This trend was noted to continue, although less dramatically, during the 2020-2021 regular season; 300 $(52 \%)$ injuries occurred during the first 2 weeks, whereas $282(48 \%)$ occurred during the second 2 weeks. The results of our study suggest that in the absence of an NFL preseason, injuries are more common during the early regular season, similar to the injury trend noted by Feeley et al. ${ }^{14}$ during training camp. However, given the unprecedented nature of the Covid-19 pandemic and its effect on the 2020-2021 NFL season, such a finding should be interpreted with this limitation in mind.

We speculate that factors similar to those proposed to account for the increased injury rate noted in the early NFL preseason also contributed to the increased injury rate noted in NFL players during weeks 1-4 of the 20202021 regular season. These factors include the relative 
deconditioning and muscle weakness that occurs during the offseason, ${ }^{16,17}$ as well as fatigue, which suggests that fatigued muscles are more vulnerable to injury. ${ }^{18,19}$ It is likely that the deconditioning of players during the early 2020 NFL regular season was similar to that of past NFL preseasons; however, during the 2020 season players were asked to play for more time and at a higher level than they would typically be expected to play during the early preseason, specifically, starters. Thus, increased time and intensity of play in the context of baseline deconditioning likely explains why the injury rate during the early 2020 NFL season was higher than the injury rate during past NFL preseasons. Our findings contribute to growing body of evidence that fatigue and deconditioning may place athletes at a higher risk for injury.

Saw et al., in their systematic review of subjective measures used to monitor athletes' responses to training, noted subjective measures, including mood disturbance, perceived stress and recovery and symptoms of stress, to be highly sensitive to an athlete's well-being in response to acute and chronic exercise loads. ${ }^{20}$ In light of these findings, the NFL may consider implementing athletes' self-reported questionnaires in order to monitor athletes' levels of exhaustion. The benefits of monitoring fatigue and athletes' well-being include revealing the need for recovery in order to prevent injury, guiding training and competition scheduling, and understanding changes in athletic performance related to fatigue., ${ }^{2,21}$ To our knowledge, no such measures have been practiced in attempt to reduce injury risk in professional football players. Future investigations may be useful in evaluation of these subjective measurement techniques and their efficacy in injury reduction in the NFL.

\section{Limitations}

This study, as well as other similar publications using the well-established multistep protocol to identify injuries in professional athletes through review of public records, is associated with several limitations. This is a database study, and incomplete data entry and inaccurate reporting of injuries could confound the season-to-season injury differences. Details regarding injury diagnosis and management, including injury severity, exact pathology, imaging reports, and exact medical clearance, were not available for all players. Because injured players were identified using public records, the possibility of reporting errors and omissions exist. We did not assess the rate of injuries over the entire season to see whether the injury rates normalized as the season went on. Our study also lacks objective measures of deconditioning to correlate with injury rates during COVID-19. Finally, there remains the possibility of selection bias in the injured group in which only "newsworthy" players injured were reported on. We attempted to minimize this bias by corroborating reported injuries with 2 additional resources, but the data are limited by what is publicly available.

\section{Conclusion}

The rate of injury in NFL players during weeks 1-4 of the 2020-2021 regular seasons was significantly higher than that of the 3 recent past NFL preseasons and regular seasons.

\section{References}

1. Pickman B. Report: NFL Scraps 2020 Preseason Amid COVID-19 Pandemic. Sports Illustr 2020; July 21. Available at. https://www.si.com/nfl/2020/07/21/nfl-preseason2020-canceled-coronavirus. Accessed May 5, 2021.

2. Mack CD, Kent RW, Coughlin MJ, et al. Incidence of lower extremity injury in the National Football League: 2015 to 2018. Am J Sports Med 2020;48:2287-2294.

3. Soligard T, Schwellnus M, Alonso JM, et al. How much is too much? (Part 1): International Olympic Committee consensus statement on load in sport and risk of injury. $\mathrm{Br}$ J Sports Med 2016;50:1030-1041.

4. Bennell KL, Malcolm SA, Wark JD, Brukner PD. Models for the pathogenesis of stress fractures in athletes. $\mathrm{Br} \mathrm{J}$ Sports Med 1996;30:200-204.

5. Dye SF. The pathophysiology of patellofemoral pain: A tissue homeostasis perspective. Clin Orthop Relat Res 2005: 100-110.

6. Edwards WB. Modeling overuse injuries in sport as a mechanical fatigue phenomenon. Exerc Sport Sci Rev 2018;46:224-231.

7. Magnusson SP, Langberg H, Kjaer M. The pathogenesis of tendinopathy: Balancing the response to loading. Nat Rev Rheumatol 2010;6:262-268.

8. Warden SJ, Davis IS, Fredericson M. Management and prevention of bone stress injuries in long-distance runners. J Orthop Sports Phys Ther 2014;44:749-765.

9. Conte SA, Thompson MM, Marks MA, Dines JS. Abdominal muscle strains in professional baseball: 19912010. Am J Sports Med 2012;40:650-656.

10. Erickson BJ, Gupta AK, Harris JD, et al. Rate of return to pitching and performance after Tommy John surgery in Major League Baseball pitchers. Am J Sports Med 2014;42: 536-543.

11. Gibson BW, Webner D, Huffman GR, Sennett BJ. Ulnar collateral ligament reconstruction in Major League Baseball pitchers. Am J Sports Med 2007;35:575-581.

12. Makhni EC, Lee RW, Morrow ZS, Gualtieri AP, Gorroochurn P, Ahmad CS. Performance, return to competition, and reinjury after Tommy John surgery in Major League Baseball pitchers: A review of 147 cases. Am J Sports Med 2014;42:1323-1332.

13. Marshall NE, Jildeh TR, Okoroha KR, Patel A, Moutzouros V, Makhni EC. Implications of core and hip injuries on Major League Baseball pitchers on the disabled list. Arthroscopy 2018;34:473-478. 
14. Feeley BT, Kennelly S, Barnes RP, et al. Epidemiology of National Football League training camp injuries from 1998 to 2007. Am J Sports Med 2008;36:1597-1603.

15. Elliott MC, Zarins B, Powell JW, Kenyon CD. Hamstring muscle strains in professional football players: A 10-year review. Am J Sports Med 201 1;39:843-850.

16. Orchard J, Marsden J, Lord S, Garlick D. Preseason hamstring muscle weakness associated with hamstring muscle injury in Australian footballers. Am J Sports Med 1997;25:81-85.

17. Croisier JL, Ganteaume S, Binet J, Genty M, Ferret JM. Strength imbalances and prevention of hamstring injury in professional soccer players: A prospective study. Am J Sports Med 2008;36:1469-1475.
18. Woods C, Hawkins RD, Maltby S, et al. The Football Association Medical Research Programme:Aan audit of injuries in professional football-analysis of hamstring injuries. Br J Sports Med 2004;38:36-41.

19. Mair SD, Seaber AV, Glisson RR, Garrett WE Jr. The role of fatigue in susceptibility to acute muscle strain injury. Am J Sports Med 1996;24:137-143.

20. Saw AE, Main LC, Gastin PB. Monitoring the athlete training response: Subjective self-reported measures trump commonly used objective measures: A systematic review. Br J Sports Med 2016;50:281-291.

21. Halson SL. Monitoring training load to understand fatigue in athletes. Sports Med 2014;44:S139-147 (Suppl 2). 


\section{Appendix}

Data sources used: http://www.nfl.com/injuries, https://www.espn.com/nfl/injuries, https://www.cbss ports.com/nfl/injuries/, https://www.pro-football-refer ence.com/players/injuries.htm, https://bleacherreport. com/nfl-injuries 